INVESTIGACIÓN

Recibido: 26/02/2019 --- Aceptado: 14/05/2019 --- Publicado: 15/12/2019

\title{
DEMOCRACIA, ESFERA PÚBLICA Y MEDIOS DE COMUNICACIÓN
}

\section{Democrazy, public sphere and media}

\author{
(iD) (8) Luisa del Rosario González¹. Universidad Nacional de Educación a Distancia \\ (UNED). España. \\ ldelrosar1@alumno.uned.es
}

\section{RESUMEN}

Este trabajo parte de una pregunta: ¿Se puede sostener una teoría de la democracia deliberativa como la que postulan Seyla Benhabib y Jürgen Habermas sin una teoría normativa de los medios de comunicación? Para responder a esta cuestión hemos ahondado en el concepto de esfera pública en las sociedades tardocapitalistas contrastando los trabajos de ambos filósofos junto a las aportaciones críticas de Nancy Fraser, autora que entendemos complementa la definición más adecuada. La esfera pública es el espacio tradicional de la deliberación y en ella incluimos a los medios de comunicación. Por eso sostenemos que, efectivamente, la democracia deliberativa debe contar con una teoría normativa de los medios de comunicación, pues a estos les corresponde el rol de intermediarios y propagadores de la deliberación, pero su estatus híbrido público-privado nos obliga a que esta teoría normativa garantice su servicio al interés general. En este marco expondremos algunos de los elementos que pueden contribuir a la formulación de esta teoría normativa y pondremos énfasis en dos de las cuestiones que creemos fundamentales, a saber, el establecimiento de la agenda de temas que se tratan en los medios de comunicación de amplias audiencias y el encuadre en el que se muestran los contenidos informativos.

PALABRAS CLAVE: Democracia deliberativa - esfera pública - medios de comunicación - opinión pública - participación política - agenda-setting - encuadre informativo.

\footnotetext{
${ }^{1}$ Luisa del Rosario González: Licenciada en Ciencias de la Información por la Universidad Complutense de Madrid. Licenciada en Antropología Social y Cultural por la Universidad Nacional de Educación a Distancia (UNED). Máster en Filosofía Teórica y Práctica por la UNED. Doctoranda en Filosofía por la UNED.
} 


\begin{abstract}
This work is based on a question: Can you sustain a theory of deliberative democracy like the one posited by Seyla Benhabib and Jürgen Habermas without a normative theory of the media? To answer this question, we have delved into the concept of the public sphere in late-capitalist societies, contrasting the works of both philosophers with the critical contributions of Nancy Fraser, author that we understand complements the most appropriate definition. The public sphere is the traditional space of deliberation and in it we include the media. That is why we argue that, in effect, deliberative democracy must have a normative theory of the media, because they are the role of intermediaries and propagators of deliberation, but their hybrid public-private status obliges us that this theory regulations guarantee their service to the general interest. In this framework we will expose some of the elements that can contribute to the formulation of this normative theory and we will emphasize two of the issues that we believe are fundamental, namely, the establishment of the agenda of topics discussed in the mass media and the frame in which the informative contents are shown.
\end{abstract}

KEY WORDS: deliberative Democracy - public sphere - media - public opinion political participation - agenda-setting - issue framing.

\title{
DEMOCRACIA, ESFERA PÚBLICA E MÍDIA
}

\section{RESUME}

Este trabalho parte de uma pergunta: se pode sustentar uma teoria da democracia deliberativa como a que postulam Seyla Benhabib e Jürgen Habermas sem uma teoria normativa dos meios de comunicação? Para responder a esta questão profundiremos no conceito de esfera pública nas sociedades tardo-capitalistas contrastando os trabalhos de ambos filósofos junto à as apartações críticas de Nancy Fraser, autora que entendemos que complementa a definição mais adequada. A esfera pública e o espaço tradicional da deliberação e nela incluímos a os meios de comunicação. Por isso sustentamos que, efetivamente, a democracia deliberativa deve contar com uma teoria normativa dos meios de comunicação, pois a eles corresponde o papel de intermediários e propagadores da deliberação, mas seu status hibrido público-privado nos obriga a que esta teoria normativa garantisse seu serviço ao interesse geral. Neste âmbito exporemos alguns dos elementos que podem contribuir a formulação desta teoria normativa e poremos ênfases em duas das questões que cremos fundamentais, a saber, o estabelecimento da agenda de temas que se tratam nos meios de comunicação de amplas audiências e o enquadre no qual se mostram os conteúdos informativos.

PALAVRAS CHAVE: democracia deliberativa - esfera pública - meios de comunicação - opinião pública - participação política - agenda - setting - enquadre informativo.

Vivat Academia. Revista de Comunicación. 15 diciembre 2019 /15 marzo 2020, nº 149, 25-44 


\section{Como citar el artículo:}

Del Rosario González, L. (2019). Democracia, esfera pública y medios de comunicación. [Democrazy, public sphere and media]. Vivat Academia. Revista de Comunicación, (149), 25-44.

doi: http:// doi.org/10.15178/va.2019.149.25-44

Recuperado de http://www.vivatacademia.net/index.php/vivat/article/view/1164

\section{INTRODUCCIÓN}

La concepción de la democracia deliberativa de Seyla Benhabib, deudora de la de Jürgen Habermas, presenta la doble consideración de norma, entendida como el conjunto de derechos y deberes, y utopía, esto es, la anticipación de una comunidad de necesidades y solidaridad (Benhabib, 1996), lo que permite abordarla como una regla verificadora de la legitimidad de una forma de gobierno (norma) y como una ética cívica (utopía) que exige la efectiva participación de los individuos en la aprobación de las normas que afectan a toda la comunidad.

Esa efectiva participación pretende dar respuesta a la exigencia de diferentes actores políticos en referencia a ámbitos en los que el principio de autonomía permanece aún bajo el influjo de por otras fuentes de legitimidad, como la tradición, las relaciones de poder o la razón de Estado.

En las teorías de la democracia deliberativa este derecho a decidir se manifiesta bajo la forma de una toma de postura cuya racionalidad se hace depender de la profundidad y amplitud del juicio que la respalda. Al proceso de formar ese juicio lo denominamos deliberación. En virtud de esos principios, llamamos democracia deliberativa a la forma política en la que las decisiones son el resultado de un proceso de intercambio de argumentos en el que participa el conjunto de la ciudadanía.

En esta definición, el verbo "participar" constituye la clave de bóveda pues en las sociedades al uso no es viable la presencia de toda la ciudadanía en la toma de decisiones. Pero esta imposibilidad material no tiene por qué menoscabar el valor de la deliberación. Lo que se debe presuponer es la ficción de una esfera pública donde no es tan trascendental la presencia física de las personas como la de sus argumentos. Sin este espacio en el que se intercambien razones no es posible concebir ni la democracia deliberativa ni la democracia sin adjetivos.

Ahora bien, este espacio de la deliberación pública en las sociedades democráticas contemporánea está mediado por empresas que desarrollan una actividad periodística al amparo del derecho a la información y la libertad de expresión. Queremos preguntarnos cuáles son las distorsiones que sobre la deliberación producen estos 
medios, generalmente empresas privadas, y cómo podría articularse una teoría normativa de los medios de comunicación que dé respuesta a las exigencias de la democracia deliberativa.

\section{OBJETIVOS}

En este artículo argumentaremos a favor de la necesidad de una teoría normativa de los medios de comunicación de amplias audiencias en el contexto de las teorías de la democracia deliberativa. Asimismo, expondremos algunos de los elementos que pueden contribuir a la formulación de dicha teoría, con particular énfasis en las cuestiones del establecimiento de la agenda de los medios y el encuadre de los contenidos informativos.

\section{METODOLOGÍA}

Partiremos de las formulaciones sobre la esfera pública desarrollada por Jürgen Habermas, Nancy Fraser y Seyla Benhabib para alcanzar un concepto que satisfaga los planteamientos normativos y utópicos de la democracia deliberativa. A continuación haremos una breve exposición de las exigencias que las teorías de la democracia deliberativa reclaman de los medios de comunicación. Continuaremos con un análisis del funcionamiento de los medios en aquellos aspectos que mayor repercusión desarrollan sobre la deliberación en la esfera pública: la agenda-setting y el encuadre de los contenidos informativos. Finalizaremos con algunas propuestas sobre el papel de los medios de comunicación en la consecución de una mejor deliberación pública en las sociedades democráticas.

\section{DISCUSIÓN}

\subsection{Democracia deliberativa y esfera pública}

En el seno de la teoría crítica, le corresponde a Jürgen Habermas el mérito de haber traído a primer plano la cuestión de la esfera pública como el espacio donde encuentra la legitimidad el ejercicio del poder político en las sociedades democráticas.

En Historia y Crítica de la opinión pública Habermas expone las condiciones que hicieron posible el nacimiento de una esfera pública en el siglo XVIII y las razones que llevaron a su colapso a finales del siglo posterior (Habermas, 2002). El filósofo alemán define la esfera pública como el lugar donde individuos privados discuten sobre aquello que comienza a entenderse como "lo público", que abarca la acción de gobiernos y los

asuntos que afectan a toda la sociedad. Se trata de una deliberación en la que se presupone la victoria del mejor argumento.

Vivat Academia. Revista de Comunicación. 15 diciembre 2019 /15 marzo 2020, nº 149, 25-44 
También es bien conocida la tesis habermasiana del declive de este espacio, fruto de la expansión de los públicos, más allá de la clase burguesa, por el nacimiento de nuevas demandas y las desigualdades sociales causadas por el pernicioso inicio del capitalismo industrial.

Así, el anterior espacio de deliberación se convertirá en un espacio de competición entre intereses contrapuestos que reclaman reformas legislativas. La ley, lejos de ser ya la expresión del interés general, se orienta ahora a satisfacer las demandas de los distintos grupos particulares. Habermas ha hablado, a este respecto, de una refeudalización de la esfera pública, cooptada por grupos de interés que negocian al margen del conocimiento público.

A esta refeudalización contribuyó el desarrollo de los medios de comunicación de amplias audiencias, que, aun siendo transmisores de información, se convirtieron, al mismo tiempo, en instituciones mercantiles a la búsqueda de consumidores a los que ofrecían una comunicación unidireccional de arriba hacia abajo privándoles la posibilidad "de hablar y replicar" (Habermas, 2000, p. 199).

Con estas dinámicas, dice Habermas, la representación y la apariencia en el escenario público sustituyen al debate. La sombría conclusión de Habermas es que ya no es posible recuperar la esfera pública primigenia y solo cabe conformarse con la estimulación de un diálogo público entre organizaciones sociales a las que podemos reclamar poco más que la adopción de mecanismos de deliberación tanto en su régimen interno como en las relaciones entre ellas (Habermas, 1974, p. 55).

En los años noventa, con textos como el prólogo a la edición alemana de 1990 de Historia y crítica de la opinión pública y la Teoría de la Acción Comunicativa, Habermas atiende las críticas que, especialmente desde las posiciones feministas, habían despertado su trabajo anterior. Se le venía a reprochar la ausencia de igualdad en esa esfera pública, de la que estaban ausentes las mujeres, la falta de apreciación de otros espacios subalternos, donde también se llevaban a cabo procesos deliberativos, y el haber obviado el potencial emancipador de los medios de comunicación.

A este respecto, fue fundamental la contribución de Nancy Fraser en su artículo "Rethinking the Public Sphere: A Contribution to the Critique of Actually Existing Democracy" (Fraser, 1990) pues la filósofa reta premisas habermasianas como la de que la participación en el espacio público presupone la igualdad de los participantes, cuando lo cierto, señala, es que en el modelo liberal las desigualdades se ponen entre paréntesis tan solo para los hombres. Esto invita a la filósofa a considerar que la participación política requiere no solo del reconocimiento de una igualdad formal, sino también de una igualdad social sustantiva. Si esas desigualdades no pueden ser tematizadas, la esfera pública se convierte en una forma de dominación sin potencial utópico alguno.

Vivat Academia. Revista de Comunicación. 15 diciembre 2019 /15 marzo 2020, nº 149, 25-44 
De forma paralela, la filósofa norteamericana distingue entre los públicos débiles, aquellos en los que se produce una deliberación no reglada, pero en el que no se toman decisiones, que vincula a un "contexto de descubrimiento"; y los públicos fuertes, constituido por los espacios en los que, como en las cámaras legislativas, se delibera siguiendo reglas y se toman decisiones, espacio que se corresponde con un "contexto de justificación".

Habermas coincide con Fraser al señalar que el espacio de la opinión pública ha de concebirse como una red, un espacio en el que se forma la influencia política y se lucha por tener influencia, pero no se toman decisiones, pues las decisiones corresponden al ámbito político legitimado para tomarlas (Habermas, 1998, p. 407).

Esta caracterización de la esfera pública en el marco del diálogo ente Habermas y Fraser es asumida por Benhabib en su versión de la democracia deliberativa. A su juicio, la esfera pública digna de una democracia deliberativa ha de cumplir con las tres exigencias de la situación ideal de habla habermasiana, con los matices que introduce la propia autora: 1) la participación igual y simétrica de todos los concernidos por los debates; 2) la posibilidad de proponer y cuestionar la agenda; y 3) la posibilidad de cuestionar las propias normas del debate.

A estos tres elementos podríamos añadir un cuarto, que sería el de la racionalidad del propio debate. Como señala Rousiley Maia (Maia, 2007, p. 73) la esfera pública debe asemejarse a la situación ideal de habla, con todas sus idealizaciones, aunque es evidente que el debate público tiene restricciones irrebasables $\mathrm{y}$, por tanto, es preciso expresarlo de forma más realista. No obstante, esta expresión es necesaria si queremos distinguir procesos que sean más o menos deliberativos. La esfera pública debe estar sometida a un criterio de racionalidad si se trata de salvar las asimetrías de poder o de amplitud los puntos de vista (Benhabib, 2006, pp. 105 y ss.).

Asumiendo esta tradición, Benhabib considera preciso enriquecer la teoría habermasiana y fraseriana de la esfera pública con unas reflexiones en torno a la obra de Hannah Arendt (Benhabib, 1994) y en particular su idea de que el espacio público es un espacio asociativo y de agrupación para la formación del poder, dimensión que se diluye en el modelo liberal. Así, al igual que Fraser y Habermas, pero con muy distinto acento, Benhabib entiende que el vínculo entre la esfera pública cívica y la esfera institucional se realiza principalmente a través de los medios de comunicación. Sin embargo, la cuestión de cómo la presencia de esa mediación puede afectar las propias condiciones que hacen que la esfera pública sea la sede de la legitimidad de las decisiones políticas no ha merecido mucha mayor consideración por parte de las teorías de la democracia deliberativa.

Vivat Academia. Revista de Comunicación. 15 diciembre 2019 /15 marzo 2020, n 149, 25-44 
Parece evidente que una teoría deliberativa de la democracia ha de responder a cómo es posible hacer depender la legitimidad del poder en la deliberación social cuando tal deliberación está mediatizada por medios de comunicación que, en los países de libre mercado, son mayoritariamente empresas privadas con ánimo de lucro.

\subsection{Medios de comunicación y democracia deliberativa}

Los medios de comunicación presentan una peculiar naturaleza. Por un lado, las cartas de derechos fundamentales garantizan los derechos a la información y la libertad de expresión a la ciudadanía. En los países democráticos de nuestro entorno, estos derechos se materializan a través de empresas privadas, lo que facilita que las corporaciones con mayores recursos económicos dispongan de numerosos y potentes altavoces para dirigirse a la sociedad. Esta realidad plantea un reto al principio de igual participación de las teorías de la democracia deliberativa, al tiempo que introduce el sistema de mercado en el proceso de deliberación pública.

Por otra parte, las teorías de las democracias deliberativas imponen a los medios la realización de un servicio público que, llegado el caso, podría perjudicar su cuenta de resultados. Al mismo tiempo, se les asegura que puedan hacer frente a la labor social, y la económica, con total autonomía y bajo el amparo de derechos que limitan las injerencias políticas sobre su funcionamiento. De esta forma, se consigue que los productos de los medios de comunicación disfruten de mayor libertad de producción y circulación que el resto de los bienes del mercado.

También es cierto que los medios de comunicación están sometidos a algunas restricciones, pues solo pueden obtener su beneficio económico demostrando a los publicistas que poseen influencia sobre la opinión pública, lo cual solo es posible si el público los reconoce como empresas de servicio público. Sin embargo, ni esto es siempre así, ni, en el caso que lo fuera, se define en lado alguno en qué consiste este servicio, cuáles son los medios legítimos para desempeñarlo, cuáles las consecuencias de su incumplimiento y qué mecanismos tiene la sociedad para sancionarlos. Bajo el axioma de que la mejor ley de prensa es aquella que no existe, nos encontramos con un sector económico bastante desregulado y bien protegido por un manto relativamente ideológico que dificulta su regulación.

Por tanto, una teoría normativa de los medios de comunicación ha de tener presente esta ambivalencia, pues, como ha señalado Habermas, de la misma forma que los medios pueden reforzar considerablemente la eficacia de los controles sociales por su potencial autoritario, esta posibilidad queda siempre en precario por el potencial emancipador que a su vez conllevan (Habermas, 2009). Esto sucede porque, a su juicio, ninguna comunicación puede quedar totalmente blindada "contra la posibilidad de ser contradicha por actos capaces de responder autónomamente de sus propios actos y de 
sus propias opiniones" (Habermas, 2010, p. 926). Considera el filósofo alemán que los medios no pueden sustraerse sin conflicto a las obligaciones procedentes de su misión periodística (Habermas, 2010, p. 927), pero no es menos cierto que ese conflicto puede llegar a ser improductivo en sociedades que hayan perdido la confianza en sus medios de comunicación.

\subsection{Hacia una teoría normativa de los medios de comunicación}

En el modelo de democracia deliberativa de Habermas, los medios de comunicación de amplias audiencias desempeñan un papel estructural en la dinamización de la deliberación política. Y aunque lo había abordado antes, será en la primera década de este siglo cuando podemos encontrar en dos textos un excelente punto de partida para una teoría de los medios de comunicación. Se trata de "Medios, mercados y consumidores: La prensa seria como espina dorsal de la esfera pública política" y "¿Tiene aún la democracia una dimensión epistémica? Investigación empírica y teoría normativa", ambos incluidos en el volumen ¡Ay, Europa! Pequeños escritos políticos (Habermas, 2009). En ellos Habermas desarrolla un esquema de la función que están llamados a desempeñar los medios de comunicación en la democracia deliberativa, al tiempo que abunda en el riesgo de la mercantilización de las empresas periodísticas y la consecuente deriva hacia la industria del entretenimiento (Habermas, 2009).

Así, según el filósofo alemán, en las sociedades actuales se crea un circuito de comunicación política en los tres niveles: el de la esfera formal de los discursos institucionalizados del sistema político, donde se delibera a propósito de las normas y se toman las decisiones vinculantes y que coincide en la definición de esfera pública fuerte de Fraser; el nivel de la comunicación de amplias audiencias basada en los medios de comunicación y en los que se manifiestan las opiniones públicas; y el nivel de la comunicación cotidiana de la sociedad, que se lleva a cabo en las esferas públicas informales y en el seno de las organizaciones, donde nacen y se configuran los puntos de vista, coincidiendo con la definición de esfera pública débil o informal.

La mediación que realizan los medios entre la esfera formal y la esfera informal solo puede ser eficaz si el público receptor es capaz de entender los discursos del sistema político adoptando posiciones razonadas hacia los temas relevantes.

El propio Habermas es consciente de que esta exigencia puede resultar "excesiva y asombrosa" a la luz de las investigaciones sobre ignorancia pública. Estos estudios parecen dibujar "un retrato desilusionador del ciudadano medio como una persona en gran medida desinformada y desinteresada" (Habermas, 2009, p. 171). Sin embargo, Habermas no descarta que a largo plazo suceda pues depende, en buena medida, de la forma en que se presentan los asuntos. 
Si los medios de comunicación cumplen su función mediadora, el resultado que se obtiene de esta circulación comunicativa entre el centro y la periferia, apunta Habermas, son las opiniones públicas razonadas, como el producto peculiar de la esfera pública. Si los medios convierten los asuntos relevantes "en problemas bien planteados", la comunicación pública desplegará y orientará en favor de la formación de la opinión y de la voluntad de los ciudadanos al tiempo que obliga al sistema político a adaptarse y a ser más transparente (Habermas, 2009, p. 162).

\subsubsection{La agenda y el encuadre de la deliberación}

El planteamiento normativo de Habermas respecto de los medios de comunicación puede parecer muy ambicioso cuando se lo contrasta con la estructura y la práctica habitual periodística en los países de nuestro entorno. En el caso de España, basta mencionar la forma polarizada en la que se informa sobre la cuestión catalana o sobre las diferentes demandas de colectivos de mujeres. No es infrecuente encontrar, aún en las cabeceras más respetables, el aliento de la confrontación y la ausencia de argumentos.

Esta actitud, antaño más propia del medio televisivo, afecta hoy incluso a señeras cabeceras de papel, un sector al que Habermas llama el de las publicaciones "razonadoras" pues, por su pausada forma de elaboración, deberían contribuir a través de artículos de opinión a la formación de juicios mejor formados, encuadres más sofisticados y mayor reflexividad. Pero, como bien señala el filósofo alemán, la formación de un juicio público razonado requiere que se disponga de buena información y de la confección de un marco que permita su comprensión, trabajo que implica investigaciones periodísticas costosas y un plantel profesional capacitado para la comprensión de la dinámica política y social $\mathrm{y}$, sobre todo, talento para la práctica deliberativa.

Habermas añade, además, la necesidad de traer al primer plano las cuestiones relevantes, incluidas las más controvertidas, con toda la información pertinente y los más sobresalientes argumentos a favor y en contra. Se refiere así a la conocida función de agenda (agenda-setting) de los medios de comunicación de amplias audiencias, según la teoría desarrollada por Donald Shaw, David Weaver y Maxwell McCombs (McCombs, 2015).

Estos autores han descubierto que la influencia que ejercen los medios de comunicación sobre la opinión pública no radica tanto en su capacidad de forzar un cambio de posición a partir de un estímulo informativo (teoría de la aguja hipodérmica) como la de establecer los asuntos sobre los que los receptores formulan sus opiniones. El efecto de agenda se demuestra observando la correlación entre las noticias publicadas y los asuntos que las personas consideran relevantes, según encuestas de opinión hechas

Vivat Academia. Revista de Comunicación. 15 diciembre 2019 /15 marzo 2020, nº 149, 25-44 
al efecto (McCombs, 2015, p. 114). La intensidad de este efecto se mide a través de una ecuación con dos parámetros: la relevancia y la incertidumbre. La relevancia apunta a la necesidad de orientación de los sujetos, según la cual, necesitamos más orientación en asuntos que nos parecen más relevantes. La incertidumbre tiene que ver con el grado de conocimiento previo que tenemos sobre estos temas: a menor conocimiento, más susceptible somos de ser influidos por los medios. A más relevancia y más incertidumbre, mayor grado de correlación en el efecto agenda-setting (McCombs, 2015, pp. 63 y ss.).

Esta capacidad de fijar la agenda plantea retos a las teorías de la democracia deliberativa, pues a los medios les corresponde seleccionar los temas de debate público, $\mathrm{y}$, al mismo tiempo, gozan del poder de cerrar la puerta de acceso a los asuntos que ubican en la esfera privada o que no consideran de interés general. Se trata de un poder sustancial que, con el desarrollo del capitalismo y la expansión de las grandes corporaciones mediáticas, ha quedado transferido a grandes corporaciones en las que se aúnan el poder económico y político. Es lo que Bernardo Díaz Nosty llama la preagenda, esto es, el conjunto de relaciones e intereses que imponen al emisor una serie de compromisos informativos, desde magnificar eventos de escaso interés, camuflando lo que simplemente es publicidad, hasta ningunear temas relevantes para salvaguardar la reputación empresarial o política del sujeto noticioso (Díaz Nosty, 2008).

La selección de los asuntos relevantes por parte de los medios obedece también a criterios que pueden ir desde la propia dinámica de las empresas periodísticas, los sesgos y capacidades de los profesionales o el coste de cubrir ciertos hechos; hasta las inconfesables influencias de los distintos poderes sociales y económicos sobre los medios.

El resultado, en cualquier caso, es que, generalmente, las voces más poderosas cuentan con mayor influencia para destacar asuntos relevantes para sus intereses particulares, mientras que las voces minoritarias, y no digamos ya las conflictivas, encuentran mucha mayor dificultad a la hora de "colocar" los suyos, aunque estos asuntos sean socialmente más relevantes que los otros. Como señala Nancy Fraser (Fraser, 1990), los medios son empresas comerciales en el marco del sistema capitalista, empresas con sus propias dinámicas económicas y sus tendencias a marginar aquellos discursos subalternos cuya vocación es, precisamente, la de poner en el punto de mira el statu quo al que las empresas de comunicación pertenecen.

La condición de la independencia de los medios respecto del poder político suele verse afectada por esta colusión de intereses mediáticos, económicos y políticos en las mismas corporaciones, intereses que se traducen en el cierre del acceso a los medios a aquellos sectores sociales que contradicen las aspiraciones comerciales o políticas de los propietarios de los medios. Estas distorsiones, afirma Habermas, son las que

Vivat Academia. Revista de Comunicación. 15 diciembre 2019 /15 marzo 2020, nº 149, 25-44 
contribuyen a que los ciudadanos se distancien de la política y a que se propaguen los estados de ánimo privatistas y antipolíticos (Habermas, 2009, pp. 172-180).

No se debe obviar, sin embargo, que la presencia de múltiples instancias de poder en la sociedad permite cierto juego de compensaciones, en la medida en que los conflictos entre esas organizaciones garantizan una relativa variedad de asuntos en los medios de comunicación. Sin embargo, esta variedad aún no significa que el formato sea adecuado para la democracia deliberativa, pues la otra forma de influencia de los medios de comunicación sobre la opinión pública se realiza a través del efecto de encuadre (issue framing). Efectivamente, definir la perspectiva del debate es aún más determinante para la calidad del proceso deliberativo e influencia en la opinión pública que el efecto de agenda-setting (McCombs, 2015, p. 51). Es decir, los medios no solo fijan buena parte de la agenda pública, el sobre qué pensamos, sino que por medio de la función de encuadre influyen en cómo lo pensamos.

Encuadrar una información es al periodismo lo que el montaje es al mundo de la cinematografía. No es lo mismo colocar un caso de violencia contra las mujeres en la sección de sucesos que en la sección de política. En la sección de sucesos se emite el mensaje de que esos casos son asuntos privados que, por su truculencia, merecen pasar al ámbito de lo público, mientras que en la sección de política se le concede la relevancia de un asunto de interés general que debe tener una respuesta legislativa y ejecutiva por parte de las administraciones. Dependiendo de cómo se encuadren las informaciones, se está orientando la deliberación pública hacia un determinado sentido y auspiciando que el consenso que se alcance venga determinado por ese encuadre. Así, en no pocas ocasiones será mejor que un problema no llegue a la agenda mediática antes de que llegue en unas inapropiadas condiciones de encuadre.

Esto puede suceder cuando se encuadran las informaciones siguiendo la pauta del conflicto, un esquema al que los medios son sensibles. Se trata de presentar la actualidad de forma polarizada, como el resultado del antagonismo entre extremos irreconciliables. En este encuadre, las opiniones más razonables son eclipsadas en beneficio de aquellas que, sobre todo en la televisión, atraen mayor audiencia. Se trata, como afirma Habermas, de sacar rédito del infotainment, un género en el que la información se presenta bajo el formato del entretenimiento, encuadrando los asuntos de tal forma que, más que a la consecución de un consenso, parecen fomentar la confrontación. Se trata de una modalidad que se ajusta mejor a los cánones del espectáculo (Habermas, 2009, p. 179).

La info-diversión va en detrimento de otros esquemas más favorables a la deliberación pública, como podrían ser los formatos de problema-solución o la simple exposición del mayor número posible de voces a propósito de un asunto. Ya se sabe que, a este respecto, un encuadre exhaustivo es tan imposible como una agenda que abarcara todos 
los temas, pero el abanico de voces puede ampliarse muchísimo más allá de los encorsetamientos que sufren los actuales medios de comunicación.

Otro de los efectos de un mal encuadre lo ofrece el tratamiento de los casos de corrupción. Una de las funciones principales de los medios de comunicación es ser los portavoces de la exigencia de responsabilidad a los funcionarios públicos. Esta misión no se satisface siendo un mero canal de transmisión de innumerables casos de corrupción tratados como sucesos, sino con una implicación en la evaluación, en la exigencia de razones y en la comprobación de la adecuación a los valores democráticos (Ettema, 2007, pp. 143-160). Además, se ha de incentivar en la ciudadanía la necesidad de involucrarse en los asuntos de interés general y participar en ellos, en vez de abocarlos al cinismo de que todas las personas que se dedican a la política son sospechosas de haber cometido alguna corrupción en el pasado. Ese denominado síndrome de Watergate ha arruinado más carreras políticas que periodísticas.

\subsubsection{Los medios de comunicación deliberativos}

Es posible distinguir cuatro tradiciones periodísticas que conforman, cada una de ellas, cuatro ecosistemas de medios de comunicación (Christians et al., 2009, pp. 19 y ss). Por una parte, el modelo corporativo define una prensa con vocación social en el marco de sociedades con marcado acento comunitarista y con un control centralizado de los propios medios. Este modelo corresponde no solo al de la prensa de los sistemas autoritarios, sino también a los de ciertas democracias de corte administrativo como las vigentes en algunos países asiáticos. Predomina una agenda establecida por los sistemas políticos y económicos, con escasa influencia de los grupos sociales minoritarios. El esquema habitual de las informaciones obedece a la estructura de presentación del problema y su solución. La finalidad de la prensa es mantener informada a la ciudadanía para asegurar su colaboración sobre lo que ya se tiene decidido hacer.

El segundo ecosistema de medios es el modelo libertario, constituido por empresas capitalistas autónomas y amparadas por una rígida libertad de prensa que impide la mínima intervención sobre ellos. Se trata de una prensa de corte individualista. Preponderante en Estados Unidos y cada vez más frecuente en el sur de Europa florece en situaciones de pluralismo polarizado, entendido como la presencia de dos tendencias políticas fuertemente enfrentadas, lo que motiva una agenda muy politizada y unos esquemas informativos basados en el conflicto y en el espectáculo. En tercer lugar nos encontraríamos con un sistema de medios de responsabilidad ciudadana, constituido por una prensa alternativa a la hegemónica y que favorece una forma de democracia cívica abierta a la mayor participación, la diversidad, el localismo y las formas de democracia directa. Se agrupan aquí los periódicos y emisoras de radio y televisión de grupos feministas, ecologistas y activistas sociales. Este modelo desempeña un importante papel de contrapunto en el interior de otros ecosistemas de medios de comunicación. La 
agenda se compone de cuestiones sociales expuestas buscando la implicación ciudadana en la resolución de los asuntos.

Finalmente, el modelo de responsabilidad social se constituye en torno a un subconjunto de cabeceras cuya actuación esté informada por el principio de responsabilidad ante la sociedad. Presente en ciertas zonas del centro y el norte de Europa, se trata de unos pocos medios de comunicación pero con muy amplia audiencia y muy regulados por las leyes estatales y locales para limitar sus operaciones en el mercado. En estos medios, la agenda suele estar más abierta a las cuestiones que interesan a los grupos sociales más significativos, producto de la presencia de sus representantes en sus consejos de redacción. En su funcionamiento óptimo, la información socioeconómica y política suele encuadrarse no a conveniencia de las corporaciones, sino bajo la perspectiva del interés general, favoreciendo la toma de decisiones mediante la deliberación sobre los distintos cursos de acción que es posible seguir.

En cualquier sociedad conviven estos modelos que, a fin de cuentas, son tipos ideales. Por otra parte, cada medio de comunicación puede compartir rasgos de cada una de las especies, siendo el dominante el que define su carácter.

Es evidente que el modelo más apropiado para la teoría de la democracia deliberativa, el de la responsabilidad social, se encuentra en serio retroceso en el conjunto de Europa debido a esa desregulación del sector. Las cabeceras que antaño desempeñaron un papel en la difusión de cierta cultura democrática han ido perdiendo su identidad debido, en muchos casos, a una arriesgada política de expansión que los ha hecho rehenes de los tenedores de deuda. La vocación de responsabilidad social hay que buscarla hoy en algunas cabeceras digitales que han recuperado prácticas periodísticas más sensibles a las cuestiones sociales y a la defensa de los valores democráticos, pero cuyas limitaciones presupuestarias les impiden alcanzar altos niveles de difusión.

En este paisaje de medios de comunicación, la democracia deliberativa tiene serias dificultades para constituirse en un instrumento práctico que extienda la deliberación social. Para que ello fuera así, la sociedad debería asumir el coste de sostener una estructura de medios de comunicación orientados por la responsabilidad social y lo suficientemente fuertes como para constituirse en el núcleo de la deliberación social. En la medida en que realizan un importante servicio público sin apenas valor de mercado, la financiación privada de estos medios tendría que reforzarse a través de una aportación pública transparente y reglada para asegurar su mayor alcance. La contrapartida a esta financiación a través de los impuestos debería ser la de una regulación que no solo los alejara de las dinámicas del mercado, sino que también los orientaran al fomento de la deliberación social. Se trataría, como señala Habermas, de asumir que la comunicación política es un bien de consumo de carácter especial, un bien 
que, al afectar a un derecho fundamental como es el de la información, no puede resolverse por la vía del mercado (Habermas, 2009, p. 131).

Este reforzamiento de la prensa privada habría de complementarse con una reorientación de los medios de comunicación públicos para mejorar su servicio a la defensa de la diversidad social. Este conglomerado de emisoras de radio y televisión, cuya difusión se extiende a la totalidad del Estado, es particularmente útil para el fomento del benhabibiano ejercicio de la mentalidad ampliada. Los medios de comunicación públicos están en las mejores condiciones para deshacer esos clichés y esas falsas generalizaciones que a menudo explican las fallas morales (Habermas, 2009, p. 134). Como señala Benhabib a propósito de esta función de los medios: "Las narraciones más estructuradas y la narración de historias pueden ayudar a formar una mentalidad ampliada y la capacidad de tomar el punto de vista de los demás en los procesos deliberativos. Aquí es donde hay un rol para el tipo correcto de periodismo y los medios de comunicación, porque el periodismo es realmente lo que nos hace presentes (re/presenta) a aquellos cuyas historias no podemos escuchar o compartir en primera persona" (Benhabib, 2008).

Así, mientras que, en términos arendtianos, los medios de comunicación de responsabilidad social fomentan el hábito de la reflexión, los medios de comunicación públicos facilitan el de la imaginación, elementos constitutivos ambos del juicio moral y político.

Poner remedio a los riesgos que para la democracia supone el excesivo crecimiento de la hoy hegemónica y dominante presencia de medios de comunicación de corte libertarios en manos de conglomerados empresariales y financieros exige un ejercicio de pasividad por parte de las administraciones públicas y la regulación de la tendencia a las absorciones, compras y concentraciones de medios tanto a nivel nacional como supranacional. Sin la liberalización mercantilista y el auxilio oportunista que prestan las administraciones públicas a estos medios de comunicación, su difusión se vería reducida al límite de lo razonable, es decir, al punto donde no pueden determinar decisivamente el curso de la deliberación pública sino participar en la misma como una voz más. Una democracia no puede aspirar a la plena legitimidad mientras continúe consintiendo la vigencia del principio de que a mayor poder económico, mayor capacidad de influencia en la esfera pública, pues eso significa trasladar la prueba de la legitimidad democrática al mercado.

Con estas reformas se puede avanzar en dar satisfacción a una de las dimensiones de la democracia deliberativa, aquella que se orienta a la consecución de decisiones colectivas a través del consenso. Pero, como ha señalado Rodney Benson (Benson, 2009, p. 182), no se debe subestimar el potencial proactivo de los medios en la esfera pública y confiarlo todo a la regulación, de la misma forma que, decimos nosotros, no se puede 
subordinar toda la actividad de la esfera pública a la consecución de dicho consenso. Por eso, hay que insistir en la tesis de Benhabib de que la participación efectiva de las personas en los procesos de toma de decisiones es al menos tan importante como la decisión que se alcance. Por tanto, hay que concluir que no se ajusta a las exigencias de la teoría crítica un sistema de medios que no contemple la presencia y protección de medios de comunicación que contribuyan a dar voz a aquellos que por las desigualdades sociales o lo minoritario de sus reivindicaciones tienen mayor dificultad para acceder a los sistemas de comunicación de alcance más amplio. Una democracia saludable que no quiera constituirse en una forma de dominación de las mayorías sobre las minorías ha de establecer los mecanismos para que estos medios de comunicación gocen de vitalidad y no encuentren obstáculos para su desarrollo. Esta es una exigencia utópica que posibilita ampliar la práctica de la democracia más allá de las fronteras institucionales.

Estas ideas para la reestructuración de los medios de comunicación no resuelven por sí solas el problema del establecimiento de la agenda pública y los esquemas bajo los que se presentan los textos informativos, problemas cuyas causas obedecen tanto a factores estructurales del propio proceso informativo como a factores coyunturales que responden a la desidia y al dominio de tradiciones y práctica periodísticas que en nada favorecen la deliberación pública.

El establecimiento de la agenda pública exige más que una reforma del estatus de las empresas, del fomento de una cultura periodística que se guíe por la exigencia de proveer a la ciudadanía de informaciones útiles para la formación de juicios sobre los asuntos de relevancia. Una guía así habría de sustituir a la hoy vigente, orientada a ofrecer una ingente cantidad de información en el tiempo más breve posible. Un periodismo útil para la práctica de la democracia deliberativa debe primar la calidad del debate sobre la cantidad de información. Como ha señalado la propia Benhabib, durante los prolegómenos de la guerra de Irak de 2003, la profusión de noticias no se tradujo en una mayor profundización del debate (Benhabib, 2008).

Esta reflexividad debe alcanzar también a la cuestión de la presentación de los textos informativos, pues los medios han de cumplir la función de servir de plataformas para esa exposición inteligible e iluminadora de las diversas opiniones políticas a la que apunta Habermas. Para que los medios pudieran cumplir esa función, J. S. Ettema señala que sería preciso que los medios respondieran a la exigencia de dar acceso a las distintas voces que puedan concurrir en el debate, reconocer a esas distintas voces como iguales en derecho y tener la sensibilidad (responsiveness) para exigir que cada una de las voces respete a todas las demás (Ettema, 2007, p. 156). La deliberación no es la expresión secuencial de opiniones individuales, ni la canalización de las opiniones en el sentido de un consenso que se ha previsto de antemano, sino razonar de forma conjunta (Christians et al., 2009, pp. 29 y ss.). Tampoco es una charla, sino una forma de diálogo orientado a 
algún tipo de acción. Para ello, el público debe ser entendido de forma plural, un público de públicos, con el ideal regulativo de hacer que todas las persona estén representadas en el discurso y puedan mostrar su preferencia por una determinada dirección de la acción (Benhabib, 2008). Deliberar significa entender las razones del otro mediante ese ejercicio de la mentalidad ampliada que debería ser un elemento central en la formación de todos los periodistas.

Para este fin, la formación periodística en las universidades puede dotar de mejores recursos argumentativos a los aspirantes a formar parte de la profesión, pues el periodista debe formarse no solo como moderador de argumentos ajenos, sino también como participante, y muy destacado, en el debate. Por ese motivo, la sociedad puede y debe exigirle responsabilidades de su ejercicio. Por tanto, se ha de estimular el cambio en las prácticas profesionales, de tal modo que la selección de los temas de la agenda pública sea el resultado de un proceso de dar y pedir razones, en el que cada uno se cuestione qué asuntos públicos podrían ameritar para aparecer en los medios de comunicación si su elección fuera sometida a las exigentes condiciones de la situación ideal de habla. Como señala Ettema, en la medida en que el periodismo es una actividad eminentemente política, los periodistas también están obligados a observar la realidad desde el punto de vista de la justicia (Ettema, 2007, p. 143).

En términos de Benhabib, observar la sociedad desde ese punto de vista supone dar respuesta a las exigencias del individuo en cuanto otro generalizado. En esto se satisface la norma. Pero los medios de comunicación han de considerar la agenda pública también en función de las exigencias del otro concreto, por la vía de dar voz a aquellos segmentos infrarrepresentados en la sociedad, segmentos que son los que más necesitados están de que su voz sea escuchada. Eso es lo que permite hablar de una dimensión utópica de la esfera pública: “En su mejor momento el periodismo hace esto; extiende tu visión del mundo al hacer que veas el mundo a través de los ojos de los demás. Informa, al tiempo que amplía la empatía a través del tiempo y el espacio. El mejor tipo de periodismo tiene esta capacidad de unir la dignidad del otro generalizado con la empatía por el otro concreto" (Benhabib, 2008).

\subsection{Medios de comunicación y democracia ¿una ensoñación utópica?}

Las teorías de la democracia deliberativa se presentan como una fórmula con la que contrastar el grado de legitimidad de los ordenamientos jurídicos y las decisiones legislativas y gubernamentales. Con esa dimensión se satisfacen las aspiraciones normativas de la teoría crítica. Pero si, con Seyla Benhabib, se pretenden satisfacer también las aspiraciones utópicas de transformar el momento presente, la democracia ha de constituirse, además, en una forma de vida, una manera de estar juntos a través de la efectiva y continua deliberación en la toma de decisiones que afectan a toda la ciudadanía. Para satisfacer esa aspiración utópica es preciso fomentar una ética cívica

Vivat Academia. Revista de Comunicación. 15 diciembre 2019 /15 marzo 2020, n 149, 25-44 
que reconozca en cada individuo el derecho a expresar sus anhelos e inquietudes y a cuestionar los arreglos que definen la forma de vida presente. $Y$ ha de dotarlo de medios para que esos anhelos y esos cuestionamientos puedan ser escuchados y tengan así la posibilidad de propiciar transformaciones.

Hay que lamentar, sin embargo, que los medios de comunicación sean instrumentos más adecuados para reforzar los valores y para perpetuar los estereotipos que para transformarlos. Si a ello sumamos la capacidad de los medios para imponer los temas de los que se debate en el espacio público y su capacidad de encuadrarlos, es fácil entender por qué se perpetúan ciertos valores que no favorecen ni el fomento de la democracia ni las promesas de libertad, igualdad y justicia.

Por ello entendemos que una teoría de la democracia deliberativa que no dé cuenta del papel que desempeñan estos instrumentos es una teoría incompleta. Si la adecuación de la esfera pública a la democracia depende de la calidad de los discursos y de la calidad de la participación, entonces la calidad de los medios de comunicación será un buen indicador de la calidad de la democracia (Calhoun, 1992, p. 2). De nada vale que amplios sectores de la sociedad refinen los conocimientos y los argumentos si los mismos no pueden ser conocidos por el público porque ven cerrado el paso hacia los medios de comunicación. El propósito de una comunicación política para la democracia consiste en ofrecer oportunidades de inclusión a todas las voces implicadas, y dicha inclusión se mide comprobando si los medios de comunicación visibilizan las desigualdades sociales, si dan voz a los distintos grupos, si admiten la permeabilidad entre las zonas de lo público y lo privado y si estimulan que los debates se conviertan en transformaciones.

Hoy no podemos esperar que las transformaciones necesarias se produzcan por el mero desarrollo de las tecnologías de la comunicación, pues nada nos asegura que esa utopía tecnológica se orienta hacia el progreso de los derechos y libertades. Sin embargo, estamos de acuerdo con Javier Muguerza (Muguerza, 2006, p. 397) en que la renuncia a la utopía finalista, a ese punto final de la historia, no implica la renuncia a la anticipación de un mundo mejor, a lo que Kant denominaba la esperanza de futuro. Aunque ese mundo mejor se consiga a base de hacer "mayor hincapié en la capacidad de la razón práctica para decir que "no" al mundo presente -para 'reaccionar contra lo que no debiera ser' y 'rebelarse ante el mal y la injusticia'". Quizás una teoría normativa de los medios de comunicación solo nos sirva para poder enarbolar legítimamente ese "no", pero esa negativa no sería poca cosa frente a la peor de las utopías: la utopía del statu quo, según la definió Robert Musil (Gómez, 2007, p. 504).

Unos medios de comunicación al servicio de la democracia constituirían, al mismo tiempo, una utopía inmanente y una utopía trascendente en los términos que las define Seyla Benhabib. Inmanente porque en la realidad se encuentra ya el germen de aquello 
que pudiendo ser, todavía no es. Trascendente porque proyecta el podría ser del futuro sobre el no es del presente. Pero esta utopía no se afana en la consecución de una sociedad ideal ni de un final feliz. Se proyecta a una sociedad más justa, más libre y más plural. Es decir, una sociedad donde se respete la norma y se permita pensar en la utopía.

Como bien ha señalado Nancy Fraser (Fraser, 1990), la esfera pública puede ser tanto un instrumento de dominación como un elemento con potencialidades emancipatorias. Qué duda cabe de que los medios de comunicación pueden inclinar la balanza hacia uno u otro lado.

\section{CONCLUSIONES}

En este artículo hemos apuntado algunas sugerencias que permitirían responder afirmativamente a la cuestión de si es posible fundamentar una teoría normativa de los medios de comunicación en las sociedades democráticas. Dichas sugerencias nos orientan hacia la necesidad de intervenir en las dinámicas de las empresas públicas y privadas de comunicación para reorientarlas al servicio del interés general, salvaguardando en todo momento los derechos fundamentales a la libertad de expresión e información. Asimismo, hemos expuesto algunas vías para lograr la socialización de la agenda pública para estimular la presencia en ella de las cuestiones relevantes que atañen al bienestar de la ciudadanía en su conjunto. Finalmente, hemos señalado las formas en que la disposición de los contenidos informativos podría contribuir a una más justa representación de los intereses de los colectivos sociales, particularmente de aquellos en situación de vulnerabilidad y desigualdad.

Con esto no hemos pretendido agotar la cuestión sino, más bien, seguir estimulando la necesidad de que, desde la filosofía, se sigan estudiando las posibilidades de adecuación de la esfera pública a las exigencias de una democracia deliberativa cuyo potencial emancipador reside en satisfacer las demandas de la norma y de la utopía en los términos en que Seyla Benhabib los ha definido.

\section{REFERENCIAS}

Benhabib, S. (1994). Deliberative Rationality and Models of Democratic Legitimacy. Constellations, 1(1), 32-33.

Benhabib, S. (1996). Democracy and Difference. Contesting the Boundaries of the Political. Princeton: Princeton University Press.

Benhabib, S. (2006). El ser y el otro en la ética contemporánea. Feminismo, comunitarismo y posmodernismo, traducción de Gabriel Zadunaisky. Barcelona: Gedisa. 
Del Rosario González, L. Democracia, esfera pública y medios de comunicación

Benhabib, S. (4, August, 2008). On the public Sphere, Deliberation, Journalism and Dignity, Seyla Benhabib interviewed by Karin Wahl-Jorgensen. Reset DOC Recuperado de https://www.resetdoc.org/story/on-the-public-sphere-deliberationjournalism-and-dignity/

Benson, R. (2009). Shaping the Public Sphere: Habermas and Beyond. The American Sociologist, 40(3), 175-197. doi: https:// doi.org/10.1007/s12108-009-9071-4

Calhoun, C. (Ed.) (1992). Habermas and the Public Sphere. Massachussets: MIT Press.

Christians, C. G. et al. (2009). Normative Theories of the Media: Journalism in Democratic Societies. Illinois: University of Illinois Press.

Díaz Nosty, B. (2008). Medios de comunicación social. En Del Campo, S. y Tezanos, J. F. (Eds.), La Sociedad. Madrid: Biblioteca Nueva.

Ettema, J. S. (2007). Journalism as Reason-Giving: Deliberative Democracy, Institutional Accountability, and The News Media Mission. Political Communication, (24), 143-160.

Fraser, N. (1990). Rethinking the Public Sphere: A Contribution to the Critique of Actually Existing Democracy, Social Text, (25/26), 56-80.

Gómez, C. (2007). Ética y utopía. En Gómez, C. y Muguerza, J. (Eds.), La aventura de la moralidad (paradigmas, fronteras y problemas de la ética). Madrid: Alianza.

Habermas, J. (1974). The Public Sphere: An Encyclopedia Article. New German Critique, (3), 49-55.

Habermas, J. (1998). Facticidad y validez. Sobre el derecho y el Estado democrático de derecho en términos de teoría del discurso, traducción de Manuel Jiménez Redondo. Madrid: Trotta.

Habermas, J. (2002). Historia y crítica de la opinión pública. La transformación estructural de la vida pública, traducción de Antonio Doménech. Barcelona: G. Gili.

Habermas, J. (2009). ¡Ay, Europa! Pequeños escritos políticos, traducción de Francisco Gil Martín. Madrid: Trotta.

Habermas, J. (2010). Teoría de la acción comunicativa, traducción de Manuel Jiménez Redondo: Madrid: Trotta.

Vivat Academia. Revista de Comunicación. 15 diciembre 2019 /15 marzo 2020, nº 149, 25-44 
Lubenow, J. A. (2012). Public Sphere and Deliberative Democracy in Jürgen Habermas: Theorethical Model and Critical Discourses. American Journal of Sciological Research, 2(4).

McCombs, M. (2015). Setting the Agenda. The Mass Media and Public Opinion, Second Edition. Cambridge: Polity Press.

Muguerza, J. (2006). Desde la perplejidad. Ensayos sobre la ética, la razón y el diálogo. Madrid: Fondo de Cultura Económica.

Rousiley, M. (2007). Deliberative Democracy and Public Sphere Typology. Estudos em Comunicação, (1), 69-102.

\section{AUTORA}

\section{Luisa del Rosario González}

Licenciada en Ciencias de la Información por la Universidad Complutense de Madrid. Licenciada en Antropología Social y Cultural por la Universidad Nacional de Educación a Distancia (UNED). Máster en Filosofía Teórica y Práctica por la UNED. Doctoranda en Filosofía por la UNED.

ldelrosar1@alumno.uned.es

Orcid ID: https:// orcid.org/0000-0003-3765-553X

Google Scholar: https://scholar.google.es/citations?user=F6giFRsAAAAI\&hl=es 